\title{
Growth and structure of ultrathin FeO films on Pt(111) studied by STM and LEED
}

\author{
M. Ritter, W. Ranke, and W. Weiss* \\ Fritz-Haber-Institut der Max-Planck-Gesellschaft, Faradayweg 4-6, 14195 Berlin, Germany
}

(Received 28 July 1997)

\begin{abstract}
The growth of iron-oxide films on $\mathrm{Pt}(111)$ prepared by iron deposition and subsequent oxidation was studied by scanning tunneling microscopy (STM) and high-resolution low-energy electron diffraction (LEED). Despite a $10 \%$ lattice mismatch to the substrate, an epitaxial growth of well-ordered films is observed. The oxide starts to grow layer by layer in a (111) orientation of the metastable cubic $\mathrm{FeO}$ structure up to a thickness of about 2.2 monolayers (ML). The completion of the second and third $\mathrm{FeO}$ layer depends on the precise oxidation temperature, and at coverages of approximately $2 \mathrm{ML}$ three-dimensional $\mathrm{Fe}_{3} \mathrm{O}_{4}(111)$ islands start to grow. The $\mathrm{FeO}(111)$ layers consist of hexagonal close-packed iron-oxygen bilayers that are laterally expanded when compared to bulk $\mathrm{FeO}$ and slightly rotated against the platinum substrate. They all exhibit oxygen-terminated unreconstructed $(1 \times 1)$ surface structures. With increasing coverage several structural film changes occur, and four coincidence structures with slightly different lateral lattice constants and rotation misfit angles against the platinum substrate are formed. In the submonolayer regime an $\mathrm{FeO}(111)$ bilayer with a lattice constant of 3.11 $\AA$ and rotated by $1.3^{\circ}$ against the platinum substrate is observed. Upon completion of the first layer the film gets compressed leading to a lattice constant of $3.09 \AA$ and a rotation misfit angle of $0.6^{\circ}$. Between 1.5 and 2 ML a coincidence structure rotated by $30^{\circ}$ against the platinum substrate forms, and at $2 \mathrm{ML}$ a nonrotated coincidence structure with a lattice constant of $3.15 \AA$ evolves. All these coincidence structures exhibit large periodicities between approximately 22 and $38 \AA$ that are visible in the STM images up to the third FeO layer surface. The LEED patterns exhibit characteristic multiple scattering satellite spots. The different coincidence structures reflect lowest-total-energy arrangements, balancing the contributions of substrate-overlayer interface energies and elastic energies within the strained oxide overlayer for each coverage. [S0163-1829(98)02311-X]
\end{abstract}

\section{INTRODUCTION}

The preparation of thin metal-oxide films is becoming an important technique in material and surface science. Single crystalline films allow us to study ordered oxide surfaces without using single-crystal samples, which sometimes are not available or may cause electrostatic charging problems when applying electron spectroscopy techniques or scanning tunneling microscopy. The properties of clean metal-oxide surfaces and the adsorption of gases thereon is of great interest in catalysis research, since not much is known about the atomic-scale surface chemistry on metal oxide catalysts yet. ${ }^{1,2}$ Magnetic oxidic multilayers of $\mathrm{Fe}_{3} \mathrm{O}_{4}$ combined with other oxides are used to study magnetic coupling across nonmagnetic barriers and between antiferromagnetic layers. ${ }^{3}$ These properties are also important for the development of magnetic-field sensors and of high-density magnetic recording media. ${ }^{4}$ Iron oxide is also utilized as catalyst material for a number of different important chemical processes, ${ }^{5}$ in particular, the technical dehydrogenation of ethylbenzene to styrene. ${ }^{6,7}$

Well-ordered oxide films can be prepared by oxidizing the surface region of the corresponding metal single crystals, which was done, for example, with several transition metals by Freund and co-workers. ${ }^{8}$ Heteroepitaxial growth can be achieved by repeatedly depositing the metal and oxidizing it afterwards, ${ }^{9-11}$ by molecular-beam epitaxy ${ }^{12}$ or by reactive vapor deposition. ${ }^{13} \mathrm{Kim}, \mathrm{Gao}$, and Chambers were able to grow single crystalline and pure phased $\mathrm{Fe}_{3} \mathrm{O}_{4}$ and $\alpha$ - $\mathrm{Fe}_{2} \mathrm{O}_{3}$ films $100-1000 \AA$ thick onto $\mathrm{MgO}$ and $\mathrm{Al}_{2} \mathrm{O}_{3}$ substrates with different orientations by plasma-assisted molecular-beam epitaxy. ${ }^{14,15}$ They found that the selective growth of these oxide phases critically depends on the growth rate determined by the iron and oxygen fluxes and the substrate temperature. High growth rates and low partial pressures are required for $\mathrm{Fe}_{3} \mathrm{O}_{4}$ while low growth rates and high oxygen pressures are needed for $\alpha-\mathrm{Fe}_{2} \mathrm{O}_{3}$. The different iron-oxide phases can transform into each other depending on the ambient conditions such as temperature and oxygen partial pressure. Their stability ranges in thermodynamic equilibrium with the oxygen gas phase are given by the iron-oxygen phase diagram. ${ }^{16}$ The substrate temperatures and oxygen partial pressures used in molecular-beam epitaxy growth of single phased iron oxide films mostly differ from the equilibrium stability ranges of these phases, indicating that the kinetics of the iron-oxide formation is determining the oxide phase that forms during epitaxial growth.

The growth mode of iron-oxide films on metal-oxide substrates depends on the lattice mismatch between the oxygen sublattices and therefore on the particular metal-oxide substrate used and its orientation. $\mathrm{Fe}_{3} \mathrm{O}_{4}$ grows layer by layer onto (100)-oriented metal-oxide substrates with small lattice mismatches, as was observed in the molecular-beam experiments by Kim, Gao, and Chambers for $\mathrm{Fe}_{3} \mathrm{O}_{4}$ on $\mathrm{MgO}(100)^{14}$ by Lind et al. for $\mathrm{Fe}_{3} \mathrm{O}_{4}$ and $\mathrm{NiO} / \mathrm{Fe}_{3} \mathrm{O}_{4}$ superlattices with sharp interfaces on $\mathrm{MgO}(100)$ substrates, ${ }^{17}$ as well as by Gaines et al., who grew smooth $\mathrm{Fe}_{3} \mathrm{O}_{4}(100)$ films about $500 \AA$ thick onto $\mathrm{MgO}(100)$ and studied them with STM afterwards. ${ }^{18}$ Nonstoichiometric $\mathrm{Fe}_{3} \mathrm{O}_{4}$ films have been produced by evaporating iron in a controlled $\mathrm{NO}_{2}$ flux, ${ }^{19}$ and a columnar growth of single crystalline $\mathrm{Fe}_{3} \mathrm{O}_{4}(111)$ particles on $\alpha-\mathrm{Al}_{2} \mathrm{O}_{3}(0001)$ was observed. ${ }^{20} \mathrm{Kim}, \mathrm{Gao}$, and Cham- 
bers also observed an initial $\mathrm{Fe}_{3} \mathrm{O}_{4}(111)$ island growth and a subsequent island coalescence on $\mathrm{Al}_{2} \mathrm{O}_{3}(0001)$ substrates, as well as faceted surfaces on $\mathrm{Fe}_{3} \mathrm{O}_{4}(110)$ films grown onto $\mathrm{MgO}(110) .{ }^{15}$

Not much is known about the details of epitaxial metaloxide growth, especially in the inital growth stage. In heteroepitaxy the growth mode on lattice mismatched substrates is always determined by substrate-interface energies, overlayer surface energies, and elastic energy in the strained overlayer that can be reduced by dislocation defects. ${ }^{21} \mathrm{Mc}-$ Kee and co-workers have demonstrated the crucial role of interfacial energy minimization at the first atomic layers for the heteroepitaxial growth mode of metal oxides. ${ }^{22}$ They found that ion size and electrostatics at the interface determine the growth mode for $\mathrm{BaTiO}_{3}(100)$ on $\mathrm{MgO}(100)$. An ordered $\mathrm{FeO}(111)$ monolayer film was grown onto $\mathrm{Pt}(111)$ and $\mathrm{Pt}(100)$ surfaces for the first time by Vurens et al. ${ }^{23}$ Later this monolayer structure was further characterized with low-energy electron diffraction (LEED) (Refs. 9 and 24) and scanning tunneling microscopy (STM) ${ }^{25}$ Galloway and coworkers proposed a model for this monolayer film, which consists of an $\mathrm{FeO}(111)$ bilayer with an expanded lateral lattice constant if compared to bulk $\mathrm{FeO}$ and rotated by $0.6^{\circ}$ against the platinum substrate. ${ }^{25}$ Photoelectron diffraction measurements reveiled an oxygen-terminated surface for this film. ${ }^{26}$ This was substantiated later by STM image calculations applying electron-scattering quantum-chemistry theory. ${ }^{27}$ Galloway and co-workers also performed some STM measurements on iron-oxide films several layers thick, where they observed coexisting $\alpha-\mathrm{Fe}_{2} \mathrm{O}_{3}$ and $\mathrm{Fe}_{3} \mathrm{O}_{4}$ islands. ${ }^{28}$

Here we present a detailed study of the initial growth stage of iron-oxide films on $\mathrm{Pt}(111)$ combining LEED and STM. The films were prepared by repeated deposition of iron and subsequent oxidation. The role of the interface structure and of the iron-oxide phase thermodynamics for the epitaxial growth is adressed. STM allows characterization of the atomic surface structures and of the film morphologies up to the $\mu \mathrm{m}$ range. With high-resolution LEED we characterize the whole sample surface and can determine average lattice constants with high precision. This makes a detailed investigation on the epitaxial film growth possible.

Several STM studies were performed on surfaces of mostly natural iron-oxide single crystals prepared by ion bombardment and annealing. Tarrach et al. studied $\mathrm{Fe}_{3} \mathrm{O}_{4}(001)$ surfaces ${ }^{29}$ Jansen, Brabers, and van Kempen $\mathrm{Fe}_{3} \mathrm{O}_{4}(110)$ surfaces. ${ }^{30}$ Lennie et al. observed two different terminations on $\mathrm{Fe}_{3} \mathrm{O}_{4}(111)$ surfaces seperated by steps and exposing iron and oxygen atoms in the topmost layer. ${ }^{31}$ They also observed different coexisting oxide phases arranged in ordered patches on the surface that they call biphase structures, namely, $\mathrm{FeO}(111)$ and $\mathrm{Fe}_{2} \mathrm{O}_{3}(0001)$ phases on $\alpha-\mathrm{Fe}_{2} \mathrm{O}_{3}(0001)$ crystals $^{32}$ as well as $\mathrm{FeO}(111)$ and $\mathrm{Fe}_{3} \mathrm{O}_{4}(111)$ phases on $\mathrm{Fe}_{3} \mathrm{O}_{4}(111)$ crystals. ${ }^{33}$ All these studies show that iron-oxide surface structures critically depend on the preparation conditions and that stoichiometric $\alpha-\mathrm{Fe}_{2} \mathrm{O}_{3}$ surfaces can not be prepared under vacuum conditions. A comparison between iron oxide surface structures formed on single-crystal samples and on epitaxially grown films may provide a deeper insight into the formation and energetics of metal-oxide surface structures.
This paper is organized as follows: In Sec. II the experimental procedures are explained, in Sec. III A the $\mathrm{FeO}$ coincidence structures that we observe on $\operatorname{Pt}(111)$ are explained together with the LEED patterns they form. The growth of the first and second $\mathrm{FeO}$ layers is presented in Secs. III B and III C, the growth of the third $\mathrm{FeO}$ layer together with the initial growth of $\mathrm{Fe}_{3} \mathrm{O}_{4}$ islands is presented in Sec. III D. The LEED beam intensity evolution during the iron-oxide film growth is presented in Sec. III E, and the experimental results are discussed in Sec. IV.

\section{EXPERIMENT}

The experiments were performed in an UHV chamber described in detail in reference. ${ }^{34}$ It is equipped with a commercial STM head (Burleigh Instruments), a backview LEED optics and a cylindrical mirror analyzer Auger spectrometer (Omicron). The base pressure of the system is 5 $\times 10^{-11}$ mbar. All STM measurements were performed in the constant current mode using tunneling currents between 0.2 and $1.0 \mathrm{nA}$ and bias voltages between 0.3 and $1.3 \mathrm{~V}$. Tungsten tips were sharpened ex situ by electrochemical etching in $\mathrm{NaOH}$. The high-resolution LEED measurements were performed in a seperate chamber equipped with a Henzler-type spot profile analysis LEED system $(\text { SPA-LEED })^{35}$ and a double pass cylindrical mirror analyzer for photoelectron spectroscopy. This chamber also has a base pressure of $5 \times 10^{-11}$ mbar.

The sample preparation was performed in both chambers in the same way. The $\mathrm{Pt}(111)$ surface is cleaned by repeated cycles of argon sputtering and annealing to $1300 \mathrm{~K}$ until it exhibited a sharp $(1 \times 1)$ LEED pattern and no AES contamination signals anymore. Iron is deposited onto this platinum surface at room temperature by thermal evaporation from an iron wire wrapped around a resistively heated tungsten wire. After the deposition the iron is oxidized for $2 \mathrm{~min}$ at temperatures between 870 and $1000 \mathrm{~K}$ in $10^{-6}$ mbar oxygen partial pressure. This produces a well-ordered first oxide layer as discussed in the following sections. To further increase the film thickness this procedure is repeated. Up to 1 ML coverage the oxidation temperature was always $T$ $=1000 \mathrm{~K}$, above $1 \mathrm{ML}$ coverage oxidation temperatures between $T=870$ and $920 \mathrm{~K}$ were applied. In the STM chamber the FeO film thickness $\Theta_{\mathrm{FeO}}$ was determined by the STM measurements. With increasing $\mathrm{FeO}$ film coverage $\Theta_{\mathrm{FeO}}$ different film structures exhibiting characteristic LEED patterns are formed. In the SPA-LEED chamber the $\mathrm{FeO}$ coverage $\Theta_{\mathrm{FeO}}$ was determined with the help of these LEED patterns for coverages above $1 \mathrm{ML}$. In the submonolayer regime the coverage was controlled by valence-band photoemission of adsorbed ethylbenzene molecules. Since at room temperature ethylbenzene only adsorbs on $\mathrm{Pt}(111)$ and not on the $\mathrm{FeO}$ covered parts of the surface, ${ }^{36}$ the adsorbate signal could be used to titrate the submonolayer coverage of the oxide overlayer and to determine the iron evaporation rate. From this evaporation rate the effective overlayer thickness $\Theta_{\mathrm{EFF}}$ corresponding to the total amount of iron deposited onto the surface is estimated. $\Theta_{\mathrm{EFF}}$ deviates from the FeO film thickness $\Theta_{\mathrm{FeO}}$ for coverages above 1.5 ML. One reason for this deviation is the growth of $\mathrm{Fe}_{3} \mathrm{O}_{4}$ islands starting at $\mathrm{FeO}$ coverages of approximately $2 \mathrm{ML}$. A second reason is a possible 


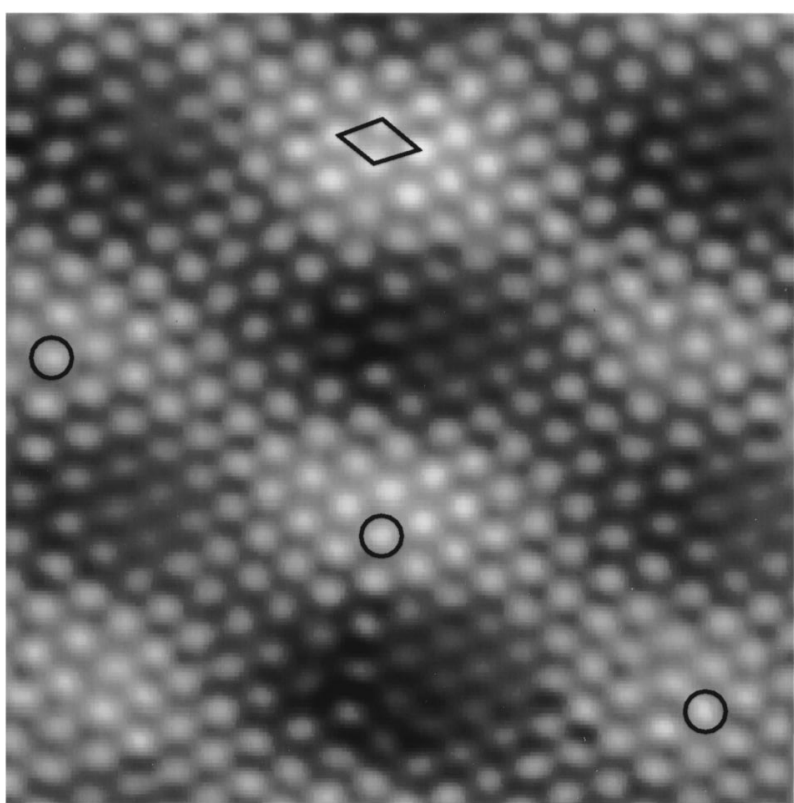

FIG. 1. $55 \times 55 \AA^{2}$ STM image of a submonolayer $\mathrm{FeO}$ film grown onto $\mathrm{Pt}(111)$. An atomic periodicity of $3.1 \AA$ is modulated by a large $25 \AA$ periodicity creating a moiré superstructure. The direction of this superstructure indicated by the marked atoms is rotated by about $11^{\circ}$ against the small $\mathrm{FeO}(111)-(1 \times 1)$ unit cell that is also indicated. $U_{T}=0.9 \mathrm{~V}, I_{T}=0.3 \mathrm{nA}$.

diffusion of iron into the platinum substrate. In the following the oxide overlayer coverage is always given in terms of the real $\mathrm{FeO}$ coverage $\Theta_{\mathrm{FeO}}$ if not stated otherwise.

\section{RESULTS}

\section{A. $\mathrm{FeO}$ coincidence structures}

Figure 1 displays a constant current $55 \times 55 \AA^{2}$ atomic resolution STM image of a FeO film less than $1 \mathrm{ML}$ thick, grown on $\mathrm{Pt}(111)$. It exhibits a hexagonal surface structure with an atomic periodicity of $3.11 \AA$ as determined precisely from the high-resolution LEED intensity scan of such a film shown in Fig. 4(b). This atomic periodicity is modulated by a larger periodicity of about $25 \AA$, which creates the moiré superstructure in the STM image. The large hexagonal unit cell of this moiré structure can be defined by the brightest atomic features in the STM image and is rotated by about $11^{\circ}$ with respect to the small $(1 \times 1)$ surface unit cell on the oxide film. This is indicated by the marked atoms with equal brightness in Fig. 1, which do not line up with the atom rows on the $\mathrm{FeO}(111)$ surface.

We propose the model shown in Fig. 2 for this submonolayer film. It consists of a laterally expanded oxygenterminated $\mathrm{FeO}(111)$ bilayer on top of the $\mathrm{Pt}(111)$ surface, where the iron atoms are seperated by $3.10 \AA$ and form rows that are rotated by $1.3^{\circ}$ with respect to the underlying platinum atom rows along the $\{-110\}$ and $\{1-10\}$ directions. For comparison the interatomic distance within the (111) planes of the cubic sodium chloride FeO bulk structure is $3.04 \AA$. In this rigid model the rotational mismatch of $\alpha=1.3^{\circ}$ between the $\mathrm{FeO}$ bilayer and the platinum substrate and the lateral FeO lattice constant of $3.10 \AA$ lead to an iron coincidence

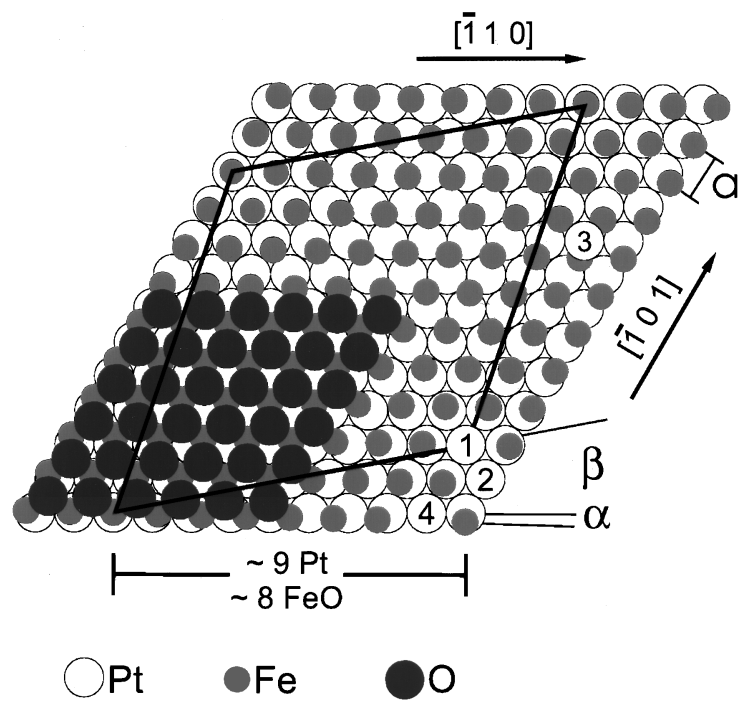

FIG. 2. Model of an $\mathrm{FeO}(111)$ bilayer on Pt(111). The overlayer has a lattice constant of $3.11 \AA$ and is rotated by $1.3^{\circ}$ against the $[-110]$ direction, forming a $\left(\begin{array}{cc}8 & 2 \\ -1 & 10\end{array}\right)$ coincidence structure with the coincidence site 1 and the large unit cell indicated. Sites 2-4 indicate coincidence sites of structures (2)-(4) as discussed in the text.

site on the platinum surface after going eight platinum lattice spacings along the $[-110]$ direction and two platinum lattice spacing along the $[-101]$ direction. This site is labeled 1 in Fig. 2 and was chosen arbitrarily as a top site on a platinum surface atom. The coincidence overlayer structure has the large unit cell indicated in Fig. 2, which is $25.4 \AA$ in size and rotated by $\beta=10.9^{\circ}$ with respect to the $(1 \times 1)$ unit cell of the $\operatorname{Pt}(111)$ surface and by $\alpha+\beta=12.2^{\circ}$ with respect to the $\mathrm{FeO}(111)-(1 \times 1)$ unit cell. It also can be described by $(\sqrt{84} \times \sqrt{84}) R 10.9^{\circ}$ or by $\left(\begin{array}{cc}8 & 2 \\ -1 & 10\end{array}\right)$ superstructure cells using the Wood or matrix notation, respectively. The angle $\alpha+\beta$ $=12.2^{\circ}$ and the lattice constant of $3.10 \AA$ obtained from this model agree reasonably with the moire angle of $11^{\circ}$ observed by STM in Fig. 1 and the $3.11 \AA$ lattice constant obtained from the LEED measurement in Fig. 4(b). In Table I these experimentally observed lattice constants and rotation misfit angles are listed together with the theoretical values expected from coincidence structure (1).

The iron-oxygen bilayer model in Fig. 2 was proposed previously by Galloway, Benitez, and Salmeron, ${ }^{25}$ who observed a very similar constant height STM image on an FeO monolayer grown onto $\mathrm{Pt}(111)$. They observed an atomic periodicity of $3.09 \AA$ and a $26 \AA$ moiré superstructure rotated by $5^{\circ} \pm 1^{\circ}$. This was explained by an iron-oxygen bilayer with a $3.09 \AA$ lattice constant and rotated by $0.6^{\circ}$ against the platinum substrate, so that the coincidence site 2 in Fig. 2 is reached after going nine platinum lattice spacings along the $[-110]$ direction and one platinum lattice spacing along the [-101] direction. Galloway, Benitez, and Salmeron observed this structure in an atomic resolution STM image. ${ }^{25}$ We observe this compressed structure (2) after completion of the first monolayer as described in Sec. III B. Galloway and co-workers applied electron-scattering quantum-chemistry theory to calculate the contrast in this STM image. ${ }^{27}$ They showed that the image contrast is not directly related to the surface topography and that for Pt tips the maxima occur 
TABLE I. FeO/Pt(111) unit cells and their orientations from SPA-LEED measurements. The structures are numbered according to their appearance with increasing FeO coverage. $\Theta_{\mathrm{EFF}}$ is the coverage according to the total amount of evaporated $\mathrm{Fe}$ and $\Theta_{\mathrm{FeO}}$ is the real $\mathrm{FeO}$ coverage as deduced from the STM measurements. The difference exists in form of $\mathrm{Fe}_{3} \mathrm{O}_{4}$ islands. The underlined numbers are the experimentally observed values, the values printed italic are those expected from the corresponding models. The FeO rows are rotated by $\alpha$ with respect to the Pt atomic rows and the superstructure unit cell vectors are rotated by $\beta$ with respect to the substrate. $\alpha+\beta$ is the "moire angle" between the overlayer atomic rows and the connecting line of the moiré maxima.

\begin{tabular}{|c|c|c|c|c|c|c|c|c|c|}
\hline No. & $\Theta_{\mathrm{EFF}}(\mathrm{ML})$ & $\Theta_{\mathrm{FeO}}(\mathrm{ML})$ & \multicolumn{3}{|c|}{ LEED structure } & $a_{\mathrm{FeO}}(\AA)$ & $\alpha$ & $\beta$ & $\alpha+\beta$ \\
\hline (1) & $<1$ & $<1$ & $\left(\begin{array}{c}8 \\
-2\end{array}\right.$ & $\left.\begin{array}{c}2 \\
10\end{array}\right)$ & $(\sqrt{84} \times \sqrt{84}) R 10.9^{\circ}$ & $\frac{3.11}{3.102}$ & $\frac{1-1.5^{\circ}}{1.3^{\circ}}$ & $10.9^{\circ}$ & $12.2^{\circ}$ \\
\hline (2) & $>1$ & $>1$ & $\left(\begin{array}{c}9 \\
-1\end{array}\right.$ & $\left.\begin{array}{c}1 \\
10\end{array}\right)$ & $(\sqrt{91} \times \sqrt{91}) R 5.2^{\circ}$ & $\frac{3.09}{3.093}$ & $\frac{\text { small }}{0.6^{\circ}}$ & $5.2^{\circ}$ & $5.8^{\circ}$ \\
\hline (3) & $\cong 2$ & $\cong 1.8$ & $\left(\begin{array}{c}8 \\
-8\end{array}\right.$ & $\left.\begin{array}{c}8 \\
16\end{array}\right)$ & $(8 \sqrt{3} \times 8 \sqrt{3}) R 30^{\circ}$ & ${\frac{38.0}{38.38^{\mathrm{a}}}}^{\mathrm{a}}$ & $\frac{30^{\circ}}{30^{\circ}}$ & & \\
\hline (4) & $>2.5$ & $>2$ & $\left(\begin{array}{l}8 \\
0\end{array}\right.$ & $\left.\begin{array}{l}0 \\
8\end{array}\right)$ & $8 \times 8$ & $\frac{3.15}{3.166}$ & $\frac{\text { small }}{0^{\circ}}$ & $0^{\circ}$ & $0^{\circ}$ \\
\hline
\end{tabular}

${ }^{\mathrm{a}}$ This is the length of the superstructure unit cell vector and not $a_{\mathrm{FeO}}$ which is not known since we have no model for this structure.

over oxygen positions. Photoelectron diffraction measurements also reveiled an oxygen-terminated surface for this $\mathrm{FeO}$ bilayer. ${ }^{26}$ Based on these findings we interpret the atomic resolution STM images we observe on $\mathrm{FeO}(111)$ films also as oxygen-terminated surface structures.

All $\mathrm{FeO}(111)$ films from submonolayer up to $2.2 \mathrm{ML}$ thickness and beyond exhibit similar hexagonal LEED patterns which are consistent with the model in Fig. 2. A schematic representation of these LEED patterns is shown in Fig. 3. The first-order platinum substrate spots are still visible and occur at the same positions as on the clean surface (crosses). They correspond to the $\mathrm{Pt}(111)-(1 \times 1)$ surface unit cell with a lattice constant of $2.77 \AA$. The oxide film also forms a hexagonal LEED pattern that is superimposed to the hexagonal platinum LEED pattern. The first-order $\mathrm{FeO}$ spots are located closer to the specular beam because of the larger $\mathrm{FeO}(111)-(1 \times 1)$ surface unit cell with a lattice constant of about $3.1 \AA$ (large dots). The formation of the satellite diffraction spots around the (00) and $\mathrm{FeO}(10)$ beams (small dots) can be discussed in terms of multiple scattering pro-

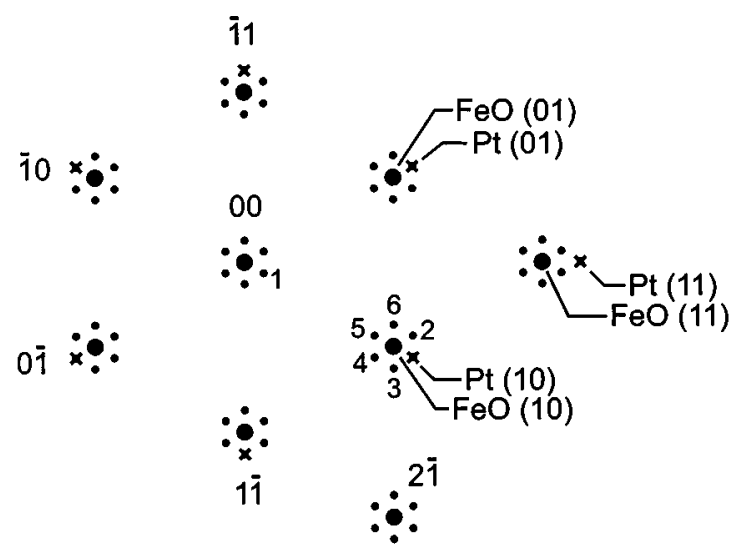

FIG. 3. Schematic LEED pattern of $\mathrm{FeO}(111)$ films on $\mathrm{Pt}(111)$. Crosses indicate platinum integer spots, large dots $\mathrm{FeO}$ integer spots, and small dots double scattering satellite spots. cesses between the platinum substrate and the oxide overlayer as well as in terms of diffraction at the large superstructure unit cell of a buckled overlayer into fractional order spots. Both descriptions lead to the same satellite spot positions that are given by linear combinations of platinum substrate and oxide overlayer surface reciprocal lattice vectors $\mathbf{g}(h k)_{\mathrm{Pt}}+\mathbf{g}(h k)_{\mathrm{FeO}}$, where $h$ and $k$ denote the indices of the integer diffraction spots. ${ }^{37}$ From the weak satellite spot intensities, if compared to the substrate and overlayer integer spot intensities, it can be concluded that multiple scattering is the dominating mechanism creating the satellite spots. This indicates a small buckling in the oxide overlayer, which is in line with STM image simulations that revealed the atomic corrugations in the STM images to be mainly due to the local electronic surface structure and not to the surface topography. ${ }^{27}$

In the multiple scattering picture satellite spot 1 near the (00) beam in Fig. 3, for example, is created by double scattering described by the scattering vector sum $\mathbf{g}(10)_{\mathrm{Pt}_{\mathrm{t}}}+\mathbf{g}$ $(-10)_{\mathrm{FeO}}$. Spot 2 near the (10) beams is created by double scattering described by $\mathbf{g}(01)_{\mathrm{Pt}}+\mathbf{g}(1-1)_{\mathrm{FeO}}$ and spot 3 by $\mathbf{g}(-11)_{\mathrm{Pt}}+\mathbf{g}(01)_{\mathrm{FeO}}$. Spot 4 is created by double scattering $\mathbf{g}(0-1)_{\mathrm{Pt}}+\mathbf{g}(11)_{\mathrm{FeO}}$, spot 5 by $\mathbf{g}(-10)_{\mathrm{Pt}}+\mathbf{g}(20)_{\mathrm{FeO}}$ and spot 6 by $\mathbf{g}(-11)_{\mathrm{Pt}}+\mathbf{g}(2-1)_{\mathrm{FeO}}$. We also observe very weak spots due to triple scattering events, which, however, are hardly visible in the gray-scale intensity plots shown in Fig. 4.

For a nonrotated $\mathrm{FeO}$ bilayer perfectly aligned to the platinum substrate we expect all diffraction beams to be sharp, neglecting step induced spot broadening at the corresponding out-of-phase electron energies. ${ }^{38}$ If domains with $\mathrm{FeO}$ bilayers rotated by different angles $\alpha$ coexist on the platinum surface, a characteristic broadening or splitting of some LEED spots independent of the electron energy (scattering vector component perpendicular to the surface) but dependent on the parallel component of the scattering vector is expected. The largest spot broadening is observed for submonolayer films. This can be seen in the high-resolution LEED intensity plot in Fig. 4(b). The gray-scale plots display 


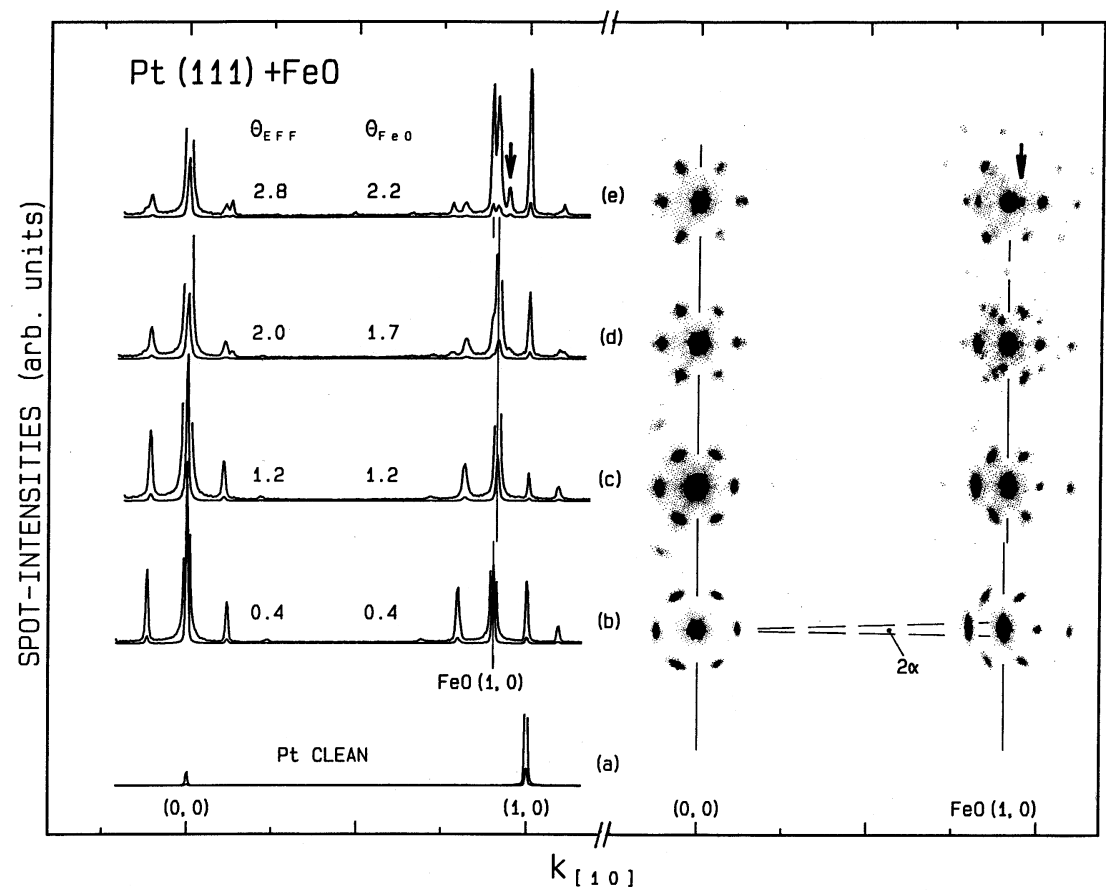

FIG. 4. LEED intensity line scans between the (00) and (10) beams (left side) and LEED pattern gray-scale plots of the region around the (00) and (10) beams for clean $\mathrm{Pt}(111)$ and for epitaxial FeO films on $\mathrm{Pt}(111)$. All curves and patterns are scaled in the same way (expanded line scans: $\times 10$ ). The coverage $\Theta_{\mathrm{EFF}}$ corresponds to the total amount of deposited Fe, the coverage $\Theta_{\mathrm{FeO}}$ corresponds to the real $\mathrm{FeO}$ coverage as deduced from the STM measurements. Above $1.5 \mathrm{ML}$ coverage both values differ because of the formation of $\mathrm{Fe}_{3} \mathrm{O}_{4}$ islands. $\mathrm{Fe}_{3} \mathrm{O}_{4}$ spots are marked by arrows. The shift of the $\mathrm{FeO}(10)$ spot between 0.4 and $1.2 \mathrm{ML}$ and its splitting at $\Theta_{\mathrm{FeO}}=2.2 \mathrm{ML}$ is emphasized by lines. The dashed lines in the lowest coverage LEED pattern on the right side indicate the (10) scattering vector directions expected for two $\mathrm{FeO}$ domains rotated by $\pm \alpha$ against the platinum substrate lattice.

the (00) and (10) beams with their surrounding double scattering satellite spots. Only the $(00)$ and the $\mathrm{Pt}(10)$ beams are round shaped, the $\mathrm{FeO}(10)$ beam is elongated perpendicular to the direction connecting the (00) and (10) beams. This is due to the coexistence of domains with different rotational mismatches between the $\mathrm{FeO}$ bilayer and the platinum substrate as discussed above. The rotation angle $\alpha$ can occur in both directions and is of the order of $1^{\circ}$ leading to domains rotated by $\alpha \approx \pm 1^{\circ}$. This leads to a splitting or an elongation of the $\mathrm{FeO}$ beams depending on the resolution of the LEED system. The spot splitting is determined by the angle $2 \alpha$ and the scattering vector length parallel to the surface as indicated in the gray-scale plot in Fig. 4(b). If several rotation angles are present a spot elongation perpendicular to the parallel scattering vector is expected. This is analogous to LEED beam broadening on mosaic crystal surfaces, which increases with increasing scattering vector perpendicular to the surface. ${ }^{39}$

The full width at half-maximum of the (00) beam does not change considerably with increasing $\mathrm{FeO}$ coverage, because no scattering vector component parallel to the surface is involved in this spot. The satellite spots around the $\mathrm{FeO}(10)$ beam are elongated according to the length of the involved overlayer scattering vectors parallel to the surface. Spots 2 and 3 are least elongated because they are created by double scattering involving the shortest overlayer scattering vector $\mathbf{g}(10)_{\mathrm{FeO}}$, whereas spots 4 and 6 are more elongated as they are created by double scattering with the longer overlayer scattering vector $\mathbf{g}(11)_{\mathrm{FeO}}$. Spot 5 is most elongated because the longest overlayer scattering vector $\mathbf{g}(20)_{\mathrm{FeO}}$ is involved.
All these spots around the $\mathrm{FeO}(10)$ beam are elongated perpendicular to the direction connecting them with the $\operatorname{Pt}(10)$ spot, a consequence of the involved overlayer scattering vector directions.

We observe four different coincidence structures with increasing $\mathrm{FeO}$ coverage $\Theta_{\mathrm{FeO}}$, which will be presented in the following sections. We numbered them $1-4$ according to the sequence of their appearance with increasing $\mathrm{FeO}$ coverage. They are listed in Table I together with their superstructure unit cells in matrix and Wood notations, their lateral lattice constants $a_{\mathrm{FeO}}$ obtained from the rigid coincidence models and observed experimentally $\left[a_{\mathrm{FeO}}\right.$ is the interatomic distance within the iron and oxygen (111) planes]. The rotation misfit angles to the platinum substrate $\alpha$ obtained from the models and observed experimentally, the misfit angles between the superstructure cell and the $\operatorname{Pt}(111)-(1 \times 1)$ cell $\beta$ as well as the moiré angle between the superstructure cell, and the $\mathrm{FeO}(111)-(1 \times 1)$ cell $\alpha+\beta$, which is observed in the STM images, are also listed.

\section{B. First layer structures}

As discussed in the previous section, for submonolayer coverages we observe the LEED pattern shown in Fig. 4(b) and the STM image shown in Fig. 1. From the broadening of the $\mathrm{FeO}(10)$ beam we derive rotational misfit angles $\alpha$ ranging between 0 and about $\pm 2^{\circ}$. The lattice constant obtained from the LEED line scan and the moiré angle $\alpha+\beta$ between the small and large unit cells on the oxide overlayer obtained from the STM image are listed in Table I and agree well with 


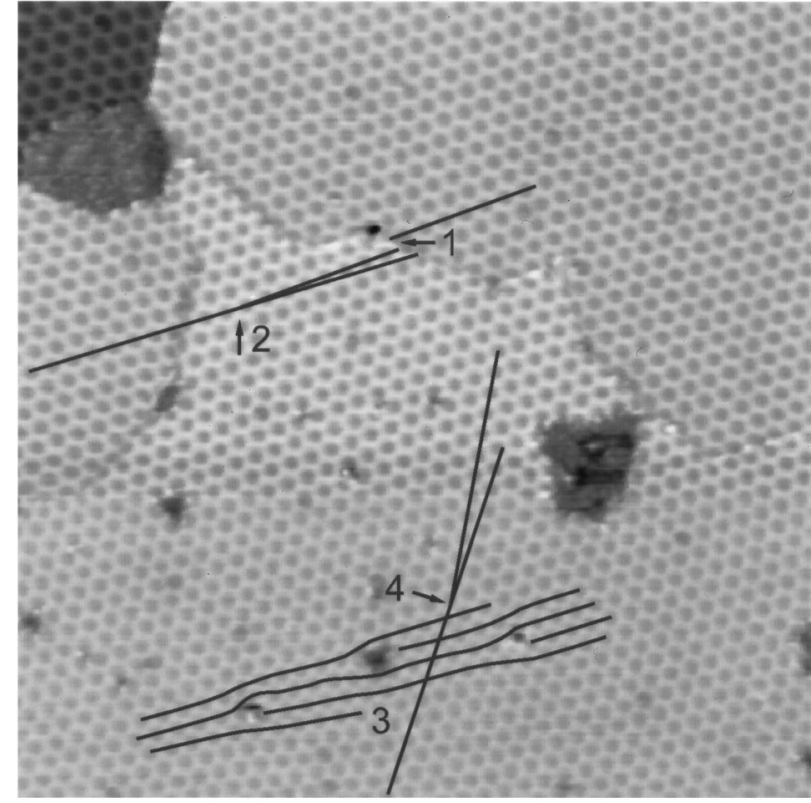

FIG. 5. $1000 \times 1000 \AA^{2}$ STM image of a $0.9 \mathrm{ML} \mathrm{FeO} \mathrm{film} \mathrm{on}$ $\mathrm{Pt}(111)$. The honeycomb moiré pattern of the $\left(\begin{array}{cc}8 & 2 \\ -1 & 10\end{array}\right)$ coincidence superstructure is visible. The defects indicated are explained in the text. $U_{T}=0.5 \mathrm{~V}, I_{T}=0.2 \mathrm{nA}$.

the values expected from a $\left(\begin{array}{cc}8 & 2 \\ -1 & 10\end{array}\right)$ coincidence structure. Model structure (1) involves rotation angles $\alpha$ of $\pm 1.3^{\circ}$, which according to the resolution of our LEED system would create a splitting of the $\mathrm{FeO}(10)$ beam or at least an intensity profile with a central minimum indicating a spot splitting. Instead, we always observe intensity profiles with a central maximum. Because the atom rows in Fig. 1 do not form straight lines but wiggled lines, additional rotational mismatches between the first layer $\mathrm{FeO}(111)-(1 \times 1)$ unit cells and the platinum substrate are created that range between $\pm 7^{\circ}$. This explains the central maximum in the $\mathrm{FeO}(10)$ spots.

The existence of different rotation misfit angles is also evident from the $1000 \times 1000 \AA^{2}$ images of an 0.9-ML-thick $\mathrm{FeO}$ film shown in Fig. 5, where several structural defects can be seen. The $25 \AA$ coincidence superstructure creates a honeycomb moire pattern clearly visible in the STM image. Between the FeO-covered regions and the dark bare platinum areas we measure a step height of $2 \AA$, which cannot be interpreted as the real topographic height difference because of the different electronic surface structures of $\mathrm{Pt}(111)$ and $\mathrm{FeO}(111)$. At the upper left corner a monoatomic platinum step seperating two $\mathrm{FeO}$ covered terraces is visible, where we measure the real platinum step height of $2.3 \AA$. Two domain boundaries meeting at the upper left can be seen, at which lateral shifts between the honeycomb coincidence superstructure cells occur as indicated for example by arrow 1 . Presumably former separated $\mathrm{FeO}$ island have grown together at these boundaries. Above the domain boundary marked by arrow 1 a well ordered superstructure without visible defects has formed. At the position marked by arrow 2 the superstructure cell direction changes by $3^{\circ}$ and arrow 4 indicates a $7^{\circ}$ direction change of the rows formed by the superstructure cells. The $7^{\circ}$ direction change can be explained by the coexistence of structures (1) and (2), the latter will be explained in the next paragraph. The $3^{\circ}$ direction change indicates the existence of superstructures with other rotation misfit angles. In the lower part of the image indicated by the number 3 several honeycomb superstructure rows end at locations where small uncovered platinum areas are present. Two honeycomb rows formerly separated by a row in between them move together at these points. They are inclined by small angles with respect to each other. The honeycomb row ending points are located along a tilt grain boundary where slightly inclined superstructure rows meet. This tilt grain boundary in an epitaxial monolayer film is the two-dimensional analogy to the well-known tilt grain boundaries in three-dimensional crystals. ${ }^{40}$ The different rotational misfits that we observe at the domain and grain boundaries also contribute in small part to the FeO LEED beam broadening that we observe on these films.

At coverages above $1 \mathrm{ML}$ the $\mathrm{FeO}(10)$ beam position moves away from the specular beam as indicated in the line scan in Fig. 4(c). This reveals a new lattice constant of 3.09 $\AA$ of the $\mathrm{FeO}$ layer, slightly smaller than the submonolayer lattice constant of $3.11 \AA$. This compression is reproducibly observed upon completion of the first $\mathrm{FeO}$ monolayer. Although we could not obtain an atomic resolution STM image of this compressed $\mathrm{FeO}$ film we propose structure (2) listed in Table I, since this structure was observed by Galloway, Benitez and Salmeron in an atomic resolution STM image. ${ }^{25}$ It has a lattice constant of $3.09 \AA$ and is rotated by $\alpha$ $=0.6^{\circ}$ against the platinum substrate. The coincidence site labeled 2 in Fig. 2 is reached after going nine platinum lattice spacings along the $[-110]$ direction and one platinum lattice spacing along the $[-101]$ direction. The $\left(\begin{array}{cc}9 & 1 \\ -1 & 10\end{array}\right)$ superstructure cell is rotated by $\beta=5.2^{\circ}$ against the $\operatorname{Pt}(111)$ $(1 \times 1)$ unit cell. Against the $\mathrm{FeO}(111)-(1 \times 1)$ unit cell it is rotated by the moire angle $\alpha+\beta=5.8^{\circ}$. A smaller rotational mismatch of this film compared to the submonolayer structure (1) is also evident from the less elongated $\mathrm{FeO}(10)$ beam and its surrounding satellite spots. This can be seen in intensity line scans of the $\mathrm{FeO}(10)$ beam along the elongation direction, which are not shown here.

\section{Second layer structures}

Figure 6 displays $1500 \times 1500 \AA^{2}$ (a) and $2000 \times 2000$ $\AA^{2}$ (b) STM images of $\mathrm{FeO}$ films 1.2 and 1.6 ML thick, respectively. The second FeO layer in Fig. 6(a) has grown in hexagonally shaped islands with step edges running along the main crystallographic directions on the $\mathrm{FeO}(111)$ surface, namely, the $\{-110\}$ and $\{1-10\}$ directions. The islands are randomly distributed on the surface. The step height measured between the first and second layer is $2.5 \AA$, which corresponds to the distance between consecutive ironoxygen (111) bilayers in the bulk $\mathrm{FeO}$ structure. At 1.2 ML coverage only the compressed monolayer structure (2) exists, which is deduced from the LEED pattern in Fig. 4(c) revealing the $3.09 \AA$ periodicity and the absence of LEED spots related to any other structures. The honeycomb moiré pattern of the $\left(\begin{array}{cc}9 & 1 \\ -1 & 10\end{array}\right)$ coincidence structure is also visible in Fig. $6(\mathrm{a})$.

On the 1.6-ML-thick FeO film shown in Fig. 6(b) the second layer exhibits hexagonal shaped holes exposing the first $\mathrm{FeO}$ layer surface. Again all steps between the first and second layer are about $2.5 \AA$ high and run along the main crystallographic directions on the $\mathrm{FeO}(111)$ surface. The ex- 

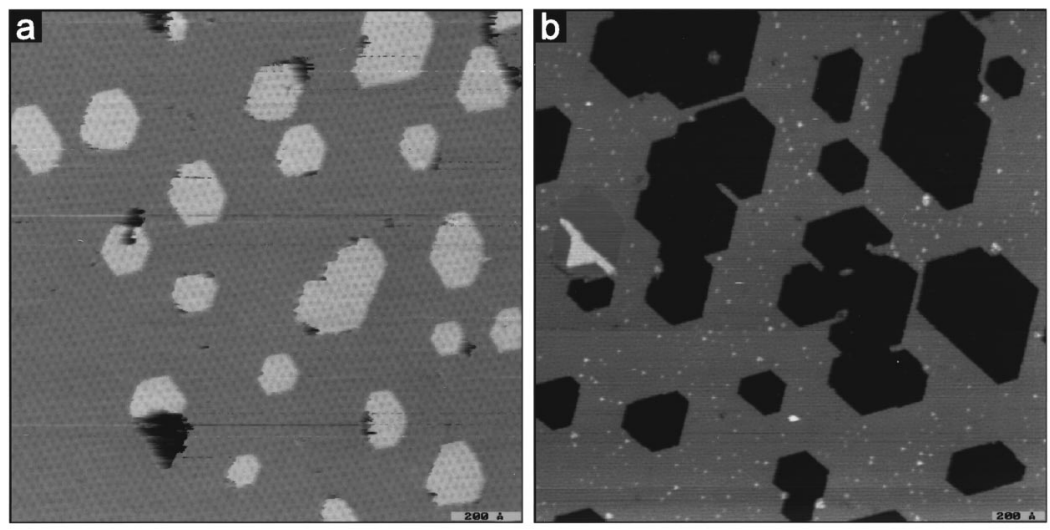

FIG. 6. (a) $1500 \times 1500 \AA^{2} \mathrm{STM}$ image of an $1.2 \mathrm{ML} \mathrm{FeO} \mathrm{film;} U_{T}=0.5 \mathrm{~V}, I_{T}=0.1 \mathrm{nA}$. (b) $2000 \times 2000 \AA^{2} \mathrm{STM}$ image of an $1.6 \mathrm{ML}$ $\mathrm{FeO}$ film; $U_{T}=1.0 \mathrm{~V}, I_{T}=0.2 \mathrm{nA}$.

posed first $\mathrm{FeO}$ layer forms the compressed monolayer structure (2) as deduced from the $3.09 \AA$ lattice constant observed in the LEED pattern in Fig. 4(d) and from the moiré superstructure observed by STM on the 1-ML-thick regions. On the second layer surface of this film a new coincidence structure is observed. This is deduced from STM measurements and from the appearance of additional LEED spots that are not related to structure (2). The gray scale plot of an $1.7 \mathrm{ML}$ film in Fig. 4(d) shows these spots around the $\mathrm{FeO}(10)$ beam. In the corresponding line scan the $\mathrm{FeO}(10)$ spot position is unchanged and corresponds to the $3.09 \AA$ lattice constant, the left shoulder of the $\mathrm{FeO}(10)$ beam is due to a fractional order spot of structure (3). Figure 7(b) shows a $90 \times 90 \AA$ STM image of this new structure. Triangles with a side length of about $35 \AA$ occur with a periodicity of about $38 \AA$ along directions rotated by $\pm 30^{\circ}$ to the $\{-110\}$ directions on the $\mathrm{Pt}(111)$ surface. Fig. 7(a) displays the LEED pattern around the $(00)$ beam of a 1.8-ML-thick film. In addition to the satellite spots of structure (2) new spots appear at positions corresponding to a $(8 \sqrt{3} \times 8 \sqrt{3}) R 30^{\circ}$ superstructure, referred to the $\operatorname{Pt}(111)-(1 \times 1)$ unit cell. In the matrix notation structure (3) is given by a $\left(\begin{array}{cc}8 & 8 \\ -8 & 16\end{array}\right)$ unit cell as listed in Table I. Since we obtained no atomic resolution STM images of this structure we do not propose a model for it. In such a model the coincidence site labeled 3 in Fig. 2 must be reached after going eight platinum spacings along the $[-110]$ and [-101] directions each. This triangle structure (3) always forms on the second layer surface at coverages between 1.5 and 2 ML.

On the left-hand side of the image in Fig. 6(b) a feature can be seen that looks like a third layer island. But the surface of this island also exhibits the triangle structure (3) in the STM image. It is located on an almost circular region about $250 \AA$ in diameter that exhibits the compressed monolayer structure (2) and which is located $2.2 \AA$ above the lowest regions where the first layer is exposed. The same step height of $2.2 \AA$, which corresponds to the step height on $\operatorname{Pt}(111)(2.26 \AA)$, is measured between the high island and the other 2-ML-thick regions of the film. Therefore, this region is the first and second $\mathrm{FeO}$ layer on top of a one-layerhigh platinum island with a diameter of $250 \AA$.

As discussed above the $(8 \sqrt{3} \times 8 \sqrt{3}) R 30^{\circ}$ triangle structure (3) starts to evolve on the second $\mathrm{FeO}$ layer surface at coverages around 1.5 ML. At coverages around 1.8 $\mathrm{ML}$ it is developed best exhibiting the highest LEED spot intensities. With further increasing coverage $\Theta_{\mathrm{FeO}}$ it gets replaced by a new $\mathrm{FeO}$ coincidence structure. In the LEED pattern of a 2.2 ML thick FeO film in Fig. $4(\mathrm{e})$ no $(8 \sqrt{3} \times 8 \sqrt{3}) R 30^{\circ}$ spots are visible anymore. In addition to the $\mathrm{FeO}(10)$ beam corresponding to the $3.09 \AA$ periodicity of structure (2), a second $\mathrm{FeO}(10)$ beam located closer to the specular beam and corresponding to a larger lattice constant of $3.15 \AA$ has evolved, which can be seen in the line scan on the left side. This agrees with STM observations showing that the triangle structure (3) completely disappears upon completion of the second $\mathrm{FeO}$ layer.

The coincidence structure (4) has a lattice constant of 3.15 $\AA$ as deduced from the LEED measurements. Figure 8 shows an atomic resolution $70 \times 70 \AA$ STM image of this structure measured on an almost completed second layer surface. It exhibits an unreconstructed $\mathrm{FeO}(111)-(1 \times 1)$ surface structure that forms a moire superstructure with a periodicity of about $22 \AA$. This distance corresponds to seven lattice spacings on the $\mathrm{FeO}(111)$ surface and is smaller than the moire superstructure period observed on structures (1) and (2). The moiré superstructure now is not rotated anymore against the small $\mathrm{FeO}(111)-(1 \times 1)$ unit cell. We propose a nonrotated $(8 \times 8)$ coincidence structure on the platinum surface as a model. The coincidence site 4 in Fig. 2 is reached after going eight platinum lattice spacings along the $[-110]$ direction. In a rigid model a $\mathrm{FeO}(111)-(8 \times 8)$ coincidence structure is obtained with a lattice constant of $3.16 \AA$, in good agreement with the experimentally observed lattice constant of $3.15 \AA$. The disappearance of the rotational mismatch is also evident from the round-shaped diffraction spots in the gray-scale LEED intensity plot in Fig. 4(e). The spots indicated by the arrows are due to $\mathrm{Fe}_{3} \mathrm{O}_{4}(111)$ islands that start to grow at this stage. The growth of these islands is discussed elsewhere. ${ }^{41}$ These islands are the reason for the deviation of the $\mathrm{FeO}$ film thickness $\Theta_{\mathrm{FeO}}$ and the effective film thickness corresponding to the total amount of deposited iron $\Theta_{\mathrm{EFF}}$.

\section{Third layer structures and $\mathrm{Fe}_{3} \mathrm{O}_{4}(111)$ island growth}

The completion of the second and third $\mathrm{FeO}$ layer and the characteristics of the $\mathrm{Fe}_{3} \mathrm{O}_{4}(111)$ island growth starting at $\mathrm{FeO}$ coverages around $2 \mathrm{ML}$ critically depend on the film oxidation temperature, which will be discussed more detailed 


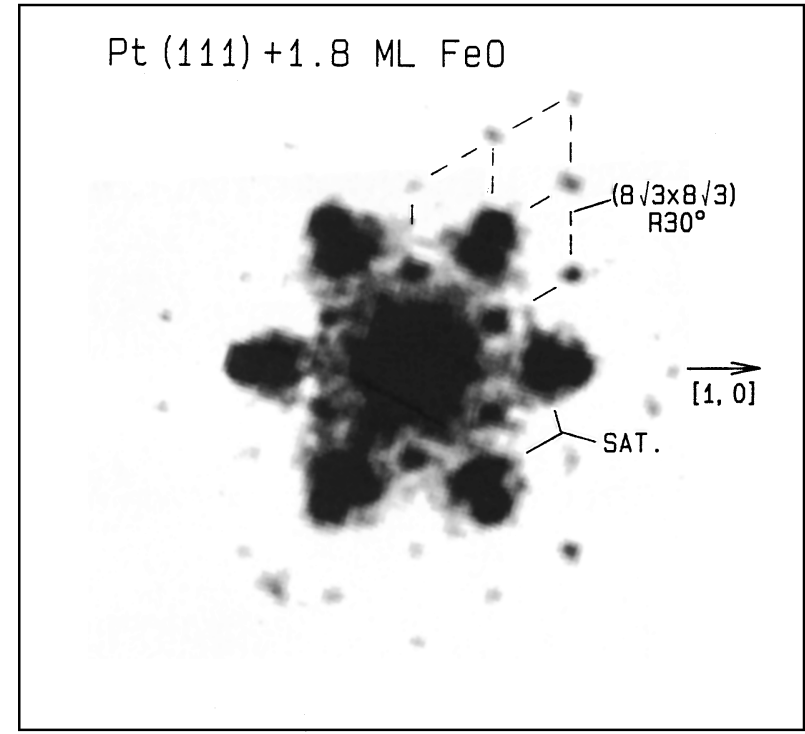

(a)

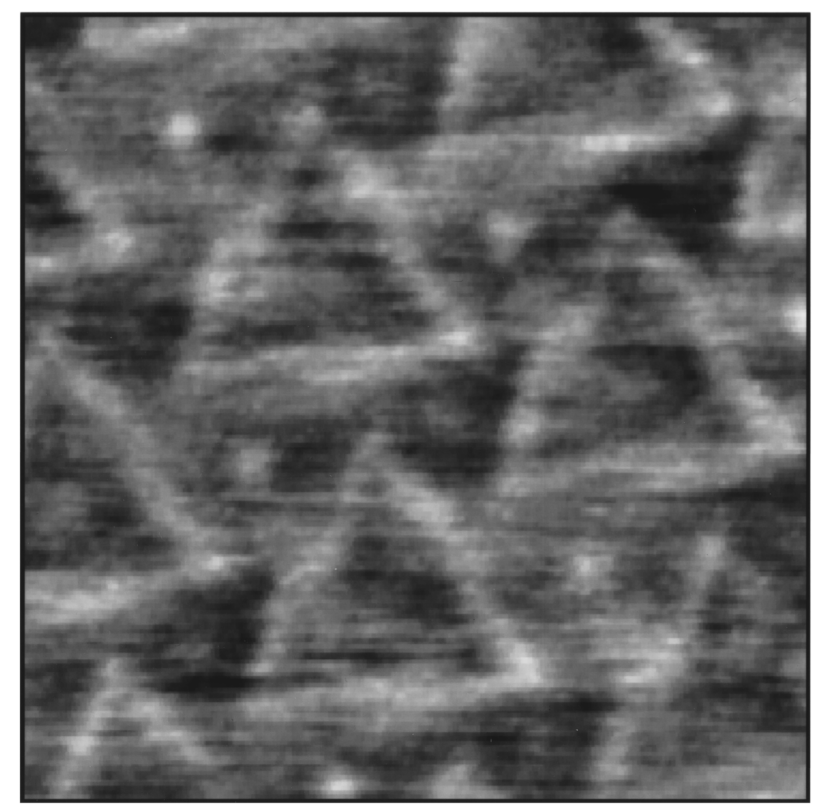

(b)

FIG. 7. (a) Gray-scale plot of the (00) LEED beam and its environment for $\Theta_{\mathrm{FeO}}=1.8 \mathrm{ML}$, where the $(8 \sqrt{3} \times 8 \sqrt{3}) R 30^{\circ}$ structure (3) is developed best. The fractional order spots of the $(8 \sqrt{3}$ $\times 8 \sqrt{3}) R 30^{\circ}$ superstructure and the double scattering satellite spots of the coexisting structure (2) are visible. The latter are elongated due to the existence of two rotation domains. (b) $90 \times 90 \AA^{2} \mathrm{STM}$ image of the $(8 \sqrt{3} \times 8 \sqrt{3}) R 30^{\circ}$ structure (3). $U_{T}=1.3 \mathrm{~V}, I_{T}$ $=1.0 \mathrm{nA}$.

in a forthcoming paper. ${ }^{41}$ This oxidation temperature dependence is demonstrated in Figs. 9 and 10, which show largearea STM images of two films prepared at $T=870$ and 920 $\mathrm{K}$, respectively. The film prepared at $T=870 \mathrm{~K}$ in Fig. 9 exhibits a closed second $\mathrm{FeO}$ layer and small third $\mathrm{FeO}$ layer islands. At this temperature $\mathrm{FeO}$ grows layer by layer up to a thickness of about $2.5 \mathrm{ML}$. $\mathrm{Fe}_{3} \mathrm{O}_{4}(111)$ islands start to grow upon completion of the second $\mathrm{FeO}$ layer, and further iron deposition and oxidation results in increasing $\mathrm{Fe}_{3} \mathrm{O}_{4}$ island sizes. The step height between the second and third layer

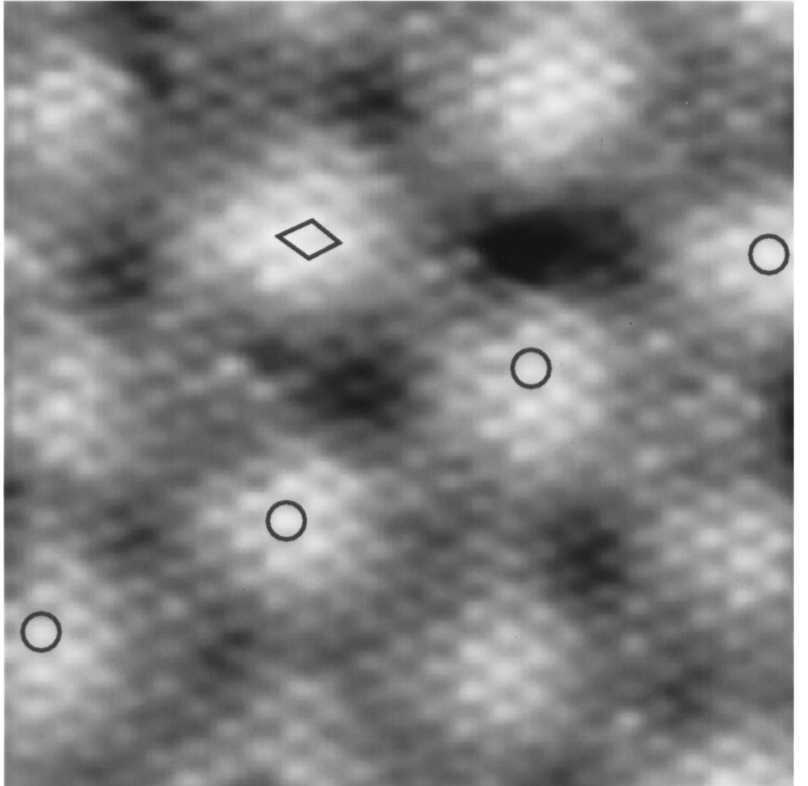

FIG. 8. $70 \times 70 \AA^{2}$ STM image of the second $\mathrm{FeO}$ layer surface exhibiting an unreconstructed, oxygen-terminated FeO(111)-(1 $\times 1)$ surface structure. The $3.15 \AA$ unit cell is indicated. The moiré superstructure of the nonrotated $(8 \times 8)$ coincidence structure is visible and its $22 \AA$ periodicity is indicated by the marked atoms. $U_{T}=0.3 \mathrm{~V}, I_{T}=1.0 \mathrm{nA}$.

again is $2.5 \AA$ corresponding to the distance between ironoxygen (111) bilayers in bulk FeO. On the 2-ML-thick film structures (2) and (4) coexist as deduced from the LEED pattern in Fig. 4(e). On the third FeO layer surface a moiré superstructure indicating the existence of the coincidence structure (4) is observed. On the film prepared at $T=920 \mathrm{~K}$

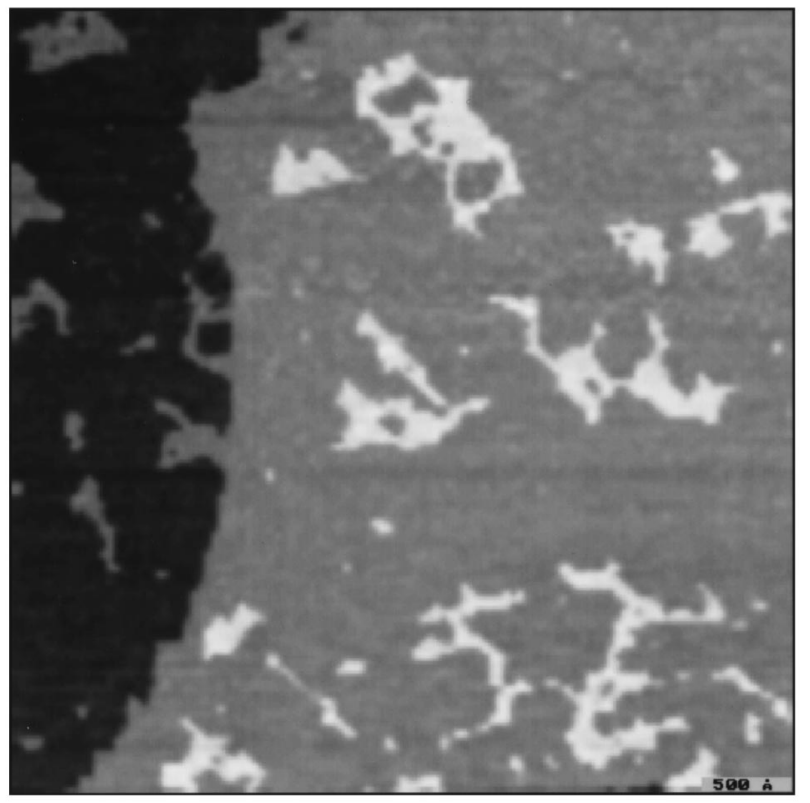

FIG. 9. $4400 \times 4400 \AA^{2}$ STM image of an $\mathrm{FeO}$ film prepared at $T=870 \mathrm{~K}, \Theta_{\mathrm{FeO}}=2.2 \mathrm{ML}$ thick. The second layer is completely closed and small third FeO layer islands can be seen. The LEED pattern of such a film is shown in Fig. 4(e). $U_{T}=1.0 \mathrm{~V}, I_{T}$ $=0.1 \mathrm{nA}$. 


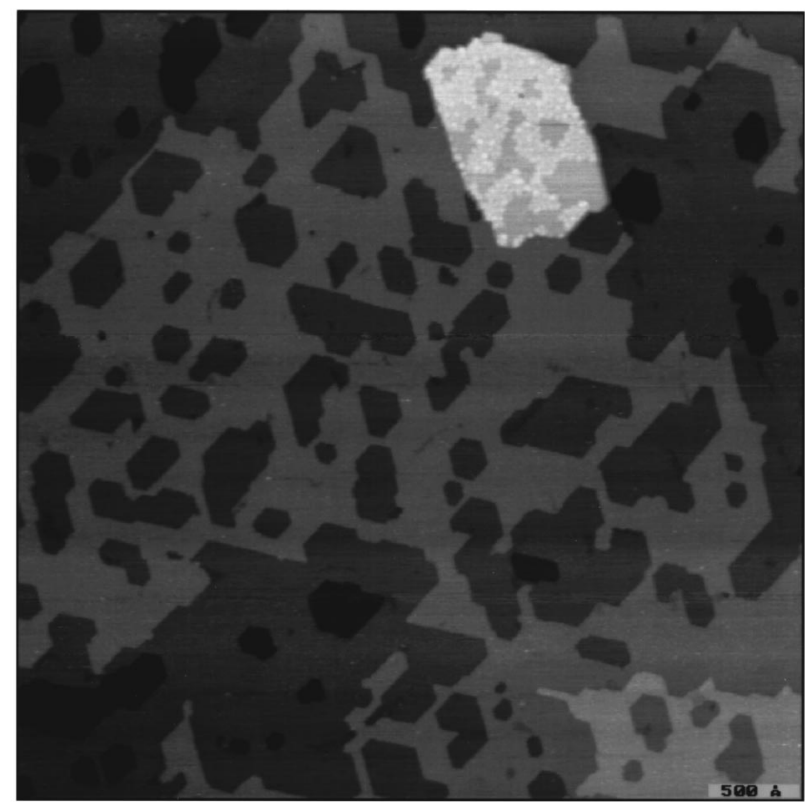

FIG. 10. $4400 \times 4400 \AA^{2}$ STM image of an $\mathrm{FeO}$ film prepared at $T=920 \mathrm{~K}, \Theta_{\mathrm{FeO}}=1.6 \mathrm{ML}$ thick. A third $\mathrm{FeO}$ layer island has formed. $U_{T}=1.0 \mathrm{~V}, I_{T}=0.9 \mathrm{nA}$.

in Fig. 10 the second layer is not completed and looks like the 1.6 ML film shown in Fig. 6(b). Only the $(8 \sqrt{3}$ $\times 8 \sqrt{3}) R 30^{\circ}$ structure (3) is observed on the second layer surface of this film. A third layer $\mathrm{FeO}$ island has formed, which is about $1200 \AA \times 500 \AA$ in size and located in the upper part of Fig. 10. The darkest areas in the image are located one $\mathrm{Pt}(111)$ interlayer spacing deeper due to platinum steps underneath the oxide film. These steps are not visible because the $\mathrm{FeO}$ coverage there changes from 1 to 2 ML as also observed on the platinum island shown in Fig. 6(b).

Since $\mathrm{FeO}$ always grows layer by layer we interpret the third layer island in Fig. 10 as the initial growth stage of an $\mathrm{Fe}_{3} \mathrm{O}_{4}(111)$ island. This interpretation is further evidenced by a different surface structure on this island. Usually third layer $\mathrm{FeO}$ islands like those in Fig. 9. always exhibit the moiré superstructure corresponding to structure (4). In contrast to that two regions with different contrasts are visible on the island surface in Fig. 10. In high-resolution scans the brighter regions show cluster like features without longrange order, whereas the darker regions are well ordered. The step height between the second FeO layers and the ordered surface regions on the island again is $2.5 \AA$. An atomic resolution $90 \times 90 \AA^{2}$ STM image of the ordered region is shown in Fig. 11, which exhibits an unreconstructed $\mathrm{FeO}(111)-(1 \times 1)$ surface. Here the film forms the same nonrotated $(8 \times 8)$ coincidence structure $(4)$ with a periodicity of about seven lattice spacings on $\mathrm{FeO}(111)$ as observed on the second layer surface of a 2 ML film shown in Fig. 8. The superstructure corrugation on the third layer surface is a little weaker. Several randomly distributed defects are observed. The missing corrugation maxima are in registry with the corrugation maxima on the defect-free surface areas, and therefore we interpret them as oxygen vacancies.

\section{E. Leed beam intensities}

The subsequent formation of the coincidence structures (1)-(4) described in the previous sections is also reflected in

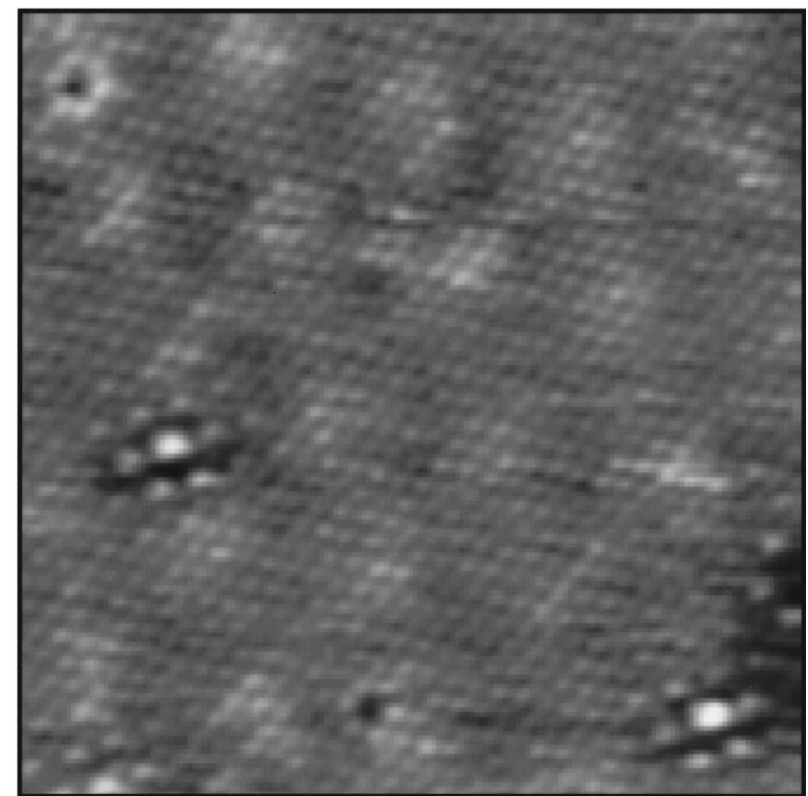

FIG. 11. $90 \times 90 \AA^{2}$ STM image of the third FeO layer surface. It exhibits a similar unreconstructed and oxygen terminated $\mathrm{FeO}(111)-(1 \times 1)$ surface structure with the moire pattern of the $(8 \times 8)$ coincidence superstructure $(4)$ as observed on the second layer surface in Fig. 8. On the lower right a defect region attributed to surface oxygen vacancies can be seen. $U_{T}=0.3 \mathrm{~V}, I_{T}=1.0 \mathrm{nA}$.

the intensities of the corresponding LEED spots. The integral beam intensities were obtained from LEED patterns as shown in Fig. 4 and are displayed in Fig. 12. Initially, the $\mathrm{FeO}(10)$ intensity increases and the $\mathrm{Pt}(10)$ intensity decreases. Structure (1) is formed at submonolayer coverages. For the chosen primary electron energy of $E_{p}=90 \mathrm{eV}$ the (00) beam of $\mathrm{Pt}(111)$ is very weak. Therefore the $(00)$ beam intensity increase is almost entirely caused by the $\mathrm{FeO}$ overlayer formation and follows exactly the increase of the $\mathrm{FeO}(10)$ intensity. At $1 \mathrm{ML}$ coverage the transformation from the submonolayer structure (1) into the compressed structure (2) takes place. This must change the dynamic FeO form factors determining the absolute beam intensities, as above $1 \mathrm{ML}$ coverage the $\mathrm{FeO}(10)$ and $(00)$ beams decrease in different ways and their intensity ratio changes. At coverages around $\Theta_{\mathrm{FeO}}=1.2 \mathrm{ML}$ only the compressed structure (2) exists. Between $\Theta_{\mathrm{FeO}}=1.5$ and $2.0 \mathrm{ML}$ the $(8 \sqrt{3}$ $\times 3 \sqrt{3}) R 30^{\circ}$ structure (3) develops, above 2.0 ML it disappears again and is replaced by the nonrotated structure (4). The compressed structure (2) still coexists but its intensity decreases as structures (3) and (4) develop. Along with the formation of structures (3) and (4) also $\mathrm{Fe}_{3} \mathrm{O}_{4}$ derived spots appear (not shown in Fig. 12), in agreement with the observation of $\mathrm{Fe}_{3} \mathrm{O}_{4}$ islands by STM. The formation of structures (3) and (4) at coverages around $\Theta_{\mathrm{EFF}}=2 \mathrm{ML}$ is accompanied by an increase of the $\mathrm{Pt}(10)$ spot intensity, which finally even exceeds the intensity on the clean platinum surface. The reason for this must be an increased scattering of structures (3) and (4) into the $\mathrm{Pt}(10)$ spot position as the oxide overlayer thickness increases.

\section{DISCUSSION}

In this work we prepared all oxide films by oxidizing iron at temperatures between 870 and $1000 \mathrm{~K}$ in $10^{-6}$ mbar oxy- 


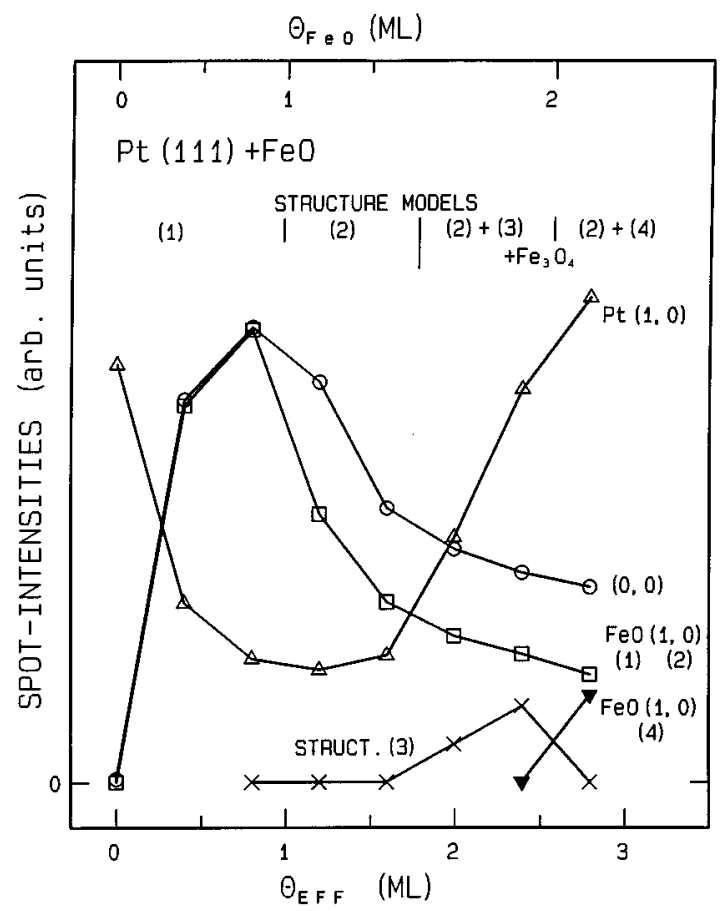

FIG. 12. LEED beam intensities at $E_{p}=90 \mathrm{eV}$ as a function of the $\mathrm{FeO}$ overlayer coverage given in the amount of deposited iron $\left(\Theta_{\mathrm{EFF}}\right.$ lower scale $)$ and in terms of the real FeO coverage $\left(\Theta_{\mathrm{FeO}}\right.$ upper scale). The curves are scaled arbitrarily in order to make their relative changes visible. The curves for $\mathrm{FeO}(10)$ (squares) and (00) (circles) beams are rescaled to each other at small coverages. The structures observed in the different coverage ranges (numbering as in Table I) are indicated.

gen partial pressure for 2 min. If solid bulk iron oxide gets into thermodynamic equilibrium with the oxygen gas phase $\mathrm{Fe}_{3} \mathrm{O}_{4}$ magnetite would coexist with $\alpha-\mathrm{Fe}_{2} \mathrm{O}_{3}$ hematite under these conditions. ${ }^{16}$ Recent calculations reveiled an equilibrium molar ratio of $25 \%: 75 \%$ between $\mathrm{Fe}_{3} \mathrm{O}_{4}$ and $\alpha-\mathrm{Fe}_{2} \mathrm{O}_{3}$ at $10^{-6}$ mbar oxygen partial pressure and $T=1000 \mathrm{~K}^{42}$ The $\mathrm{FeO}$ wustite phase is thermodynamically stable only at temperatures above $840 \mathrm{~K}$. At an oxygen partial pressure of $10^{-6} \mathrm{mbar} \mathrm{FeO}$ is stable only at a temperature of about 1700 $\mathrm{K}$, but not under the preparation conditions we applied. ${ }^{43}$ As $\mathrm{Fe}_{3} \mathrm{O}_{4}$ and $\alpha-\mathrm{Fe}_{2} \mathrm{O}_{3}$ are the stable phases at our preparation conditions, the interaction with the platinum surface must stabilize the initial formation of metastable $\mathrm{FeO}$ films. On lattice mismatched substrates epitaxial growth is determined by the interface energy between the substrate and the first strained layer and by the energy of the islands in the case of island formation. The latter is given by the sum of the island surface energies and the island-substrate interface energy that may contain dislocation defects. ${ }^{21}$ A stable interface structure is formed between an expanded first $\mathrm{FeO}(111)$ layer and the $\mathrm{Pt}(111)$ surface. $\mathrm{FeO}$ continues to grow layer by layer, leading to an increasing elastic energy within the strained overlayer, until around $2 \mathrm{ML}$ thickness $\mathrm{Fe}_{3} \mathrm{O}_{4}(111)$ islands start to grow. Both, the elastic energy increase and the thermodynamic stability of $\mathrm{Fe}_{3} \mathrm{O}_{4}$ are the driving forces for the island formation around $2 \mathrm{ML} \mathrm{FeO}$ coverage.

The crucial role of interfacial energy minimization at the first atomic layers for the heteroepitaxial growth of oxides was demonstrated by McKee et al., who found that ion size and electrostatics at the interface play a dominant role for the growth mode of $\mathrm{BaTiO}_{3}(100)$ on $\mathrm{MgO}(100){ }^{22}$ Similar effects might determine the initial stage of iron-oxide growth on $\mathrm{Pt}(111)$. The large number of successively formed and often coexisting $\mathrm{FeO}$ coincidence structures on $\mathrm{Pt}(111)$ with slightly different lattice constants and rotation misfit angles seems confusing. They must reflect lowest total-energy arrangements, balancing the contributions of substrateoverlayer interface energies and strain energies within the oxide layer for each coverage. These lowest-energy configurations are always coincidence structures. This is clearly evidenced by the observation of three $\mathrm{FeO}$ structures with different lattice constants, structures (1), (2), and (4), each having a rotation misfit angle against the platinum substrate that fits only to one particular coincidence structure. The rotated structure (1) is the coincidence structure with the lowest substrate-overlayer interface energy, because at submonolayer coverages the elastic energy within the laterally expanded oxide overlayer lattice is still small and overbalanced by the energy gain due to the formation of the lowestenergy interface structures. This situation changes upon completion of the first monolayer, when the compressed structure (2) is formed and the $\mathrm{FeO}$ lattice clicks into new coincidence sites on the substrate surface. Now the oxide overlayer has reduced its strain energy by the lattice constant compression for the price of a less favorable coincidence interface structure, which continues to exist above $2 \mathrm{ML}$ coverage. Between 1.5 and $2 \mathrm{ML}$ coverage the $(8 \sqrt{3}$ $\times 8 \sqrt{3}) R 30^{\circ}$ structure (3) forms which obviously is a transition structure that transforms further into the expanded unrotated $(8 \times 8)$ structure (4) upon completion of the second layer. Structure (2) first coexists with structure (3) and then with (4). Structure (4) is also observed on the third layer surface and is the most expanded one. The reason for its stability is not clear, as one would expect thicker $\mathrm{FeO}$ films to adopt the properties of bulk $\mathrm{FeO}$. Perhaps the $\mathrm{Fe}_{3} \mathrm{O}_{4}$ islands have an influence on the stability of structure (4) within their environment.

All observed coincidence structures have expanded lattice constants $(3.09-3.15 \AA)$ when compared to the bulk value of $\mathrm{FeO}(3.04 \AA)$. A reduced interplanar $\mathrm{Fe}-\mathrm{O}$ spacing of $0.65 \AA$ compared to the bulk spacing of $1.25 \AA$ was obtained on the $\mathrm{FeO}$ (111) monolayer film by photoelectron diffraction, which was explained by the lateral expansion of the $\mathrm{FeO}$ lattice. ${ }^{26}$ However, a $50 \%$ reduction of the interlayer spacing seems very large to be caused by a lateral expansion of $1.6 \%$. We cannot determine the topographic height difference between the $\mathrm{Pt}(111)$ substrate and the first $\mathrm{FeO}$ layer surface because of their different electronic surface structures. However, we observe the $\mathrm{FeO}$ bulk step height of $2.5 \AA$ between the first and second and between the second and third $\mathrm{FeO}$ layers, which all are laterally expanded, too. An angle dependent $\mathrm{x}$-ray absorption study also reveiled the $\mathrm{FeO}$ bulk interlayer distance between the iron and oxygen planes in $\mathrm{FeO}(111)$ films grown on $\mathrm{Pt}(111){ }^{44}$

All $\mathrm{FeO}(111)$ films form oxygen terminated unreconstructed $(1 \times 1)$ surface structures based on the STM calculations performed by Galloway and co-workers for the $\mathrm{FeO}$ monolayer film with structure (2). On a single-crystal sample an unreconstructed polar surface termination would be unstable, because its surface dipole leads to a diverging surface 
free energy. ${ }^{45}$ Polar surfaces can be stabilized by reconstructions, adatoms or vacancies that reduce the surface charge thereby lowering the surface energy. ${ }^{46} \mathrm{~A}(2 \times 2)$ LEED pattern was observed on thin $\mathrm{FeO}(111)$ films prepared by oxidion of an $\mathrm{Fe}(110)$ single crystal surface, and an octopolar reconstruction was proposed for this surface. ${ }^{47}$ The unreconstructed polar surfaces of the ultrathin $\mathrm{FeO}$ films on $\mathrm{Pt}(111)$ must be stabilized by an image dipole in the platinum substrate underneath, which compensates the dipole in the oxide overlayer. On the third FeO layer surface in Fig. 10 we observe oxygen vacancies, which reduce the polar $\mathrm{FeO}(111)$ surface energy on the somewhat thicker $\mathrm{FeO}$ film. This surface energy lowering might be the driving force for the defect formation, as iron cation vacancies and not oxygen vacancies are the predominant defects occurring in bulk $\mathrm{Fe}_{1-x} \mathrm{O}$ wustite, which for that reason exhibits large deviations from stoichiometry. ${ }^{48}$

\section{SUMMARY}

The initial growth of $\mathrm{FeO}$ on $\mathrm{Pt}(111)$ was studied by scanning tunneling microscopy and high resolution low energy electron diffraction. The $\mathrm{FeO}$ oxide grows layer by layer forming a very stable first layer on the $\operatorname{Pt}(111)$ surface. At submonolayer coverages this first layer consists of an oxygen terminated $\mathrm{FeO}(111)$ bilayer that is laterally expanded if compared to bulk $\mathrm{FeO}$ and rotated by $1.3^{\circ}$ against the platinum substrate. This leads to a $\left(\begin{array}{cc}8 & 2 \\ -1 & 10\end{array}\right)$ coincidence structure with respect to the $\operatorname{Pt}(111)$ surface. With increasing coverage different coincidence structures with different $\mathrm{FeO}$ lattice constants and rotation misfit angles are formed. They reflect lowest total energy arrangements balancing the corresponding interface and elastic energies within the strained oxide overlayer for each coverage. Around $2 \mathrm{ML} \mathrm{FeO}$ coverage the thermodynamic stable $\mathrm{Fe}_{3} \mathrm{O}_{4}$ phase starts to grow in its bulk structure, forming (111) oriented three-dimensional islands on top of the lattice mismatched platinum substrate or on top of the expanded first $\mathrm{FeO}$ layer. All films exhibit oxygen terminated unreconstructed $\mathrm{FeO}(111)-(1 \times 1)$ surface structures. These polar surfaces are stabilized by an image dipole in the platinum substrate. On the third $\mathrm{FeO}$ layer surface oxygen vacancies are formed that stabilize the polar surface by reducing the surface charge.

\section{ACKNOWLEDGMENT}

We thank Manfred Swoboda for his excellent technical assistance as well as Robert Schlögl for helpful discussions.
*Author to whom correspondence should be addressed. Fax: +49

30 84134401. Electronic address: weiss_w@fhi-berlin.mpg.de

${ }^{1}$ Gabor A. Somorjai, Introduction to Surface Chemistry and Catalysis (John Wiley \& Sons, New York, 1994).

${ }^{2}$ H. H. Kung, Transition Metal Oxides: Surface Chemistry and Catalysis (Elsevier, New York, 1991).

${ }^{3}$ P. J. van der Zaag, R. M. Wolf, A. R. Ball, C. Bordel, L. F. Feiner, and R. M. Jungblut, J. Magn. Magn. Mater. 148, 346 (1995).

${ }^{4}$ J. C. Mallinson, The Foundations of Magnetic Recording, 2nd ed. (Academic, New York, 1993).

${ }^{5}$ J. W. Geus, Appl. Catal. 25, 313 (1986).

${ }^{6}$ M. Muhler, R. Schlögl, and G. Ertl, J. Catal. 138, 413 (1992).

${ }^{7}$ D. Zscherpel, W. Weiss, and R. Schlögl, Surf. Sci. 382, 326 (1997).

${ }^{8}$ H.-J. Freund, Angew. Chem. 109/5, 444 (1997).

${ }^{9}$ W. Weiss and G. A. Somorjai, J. Vac. Sci. Technol. A 11, 2138 (1993).

${ }^{10}$ K. Takeuchi, S. S. Perry, M. Salmeron, and G. A. Somorjai, Surf. Sci. 323, 30 (1995).

${ }^{11}$ A. B. Boffa, H. C. Galloway, P. W. Jacobs, J. J. Benitez, J. D. Batteas, M. Salmeron, A. T. Bell, and G. A. Somorjai, Surf. Sci. 326, 80 (1995).

${ }^{12}$ B. A. Parkinson and F. S. Ohuchi, K. Ueno, and A. Koma, Appl. Phys. Lett. 58, 472 (1991).

${ }^{13}$ T. Fujii, M. Takano, R. Katano, Y. Bando, and Y. Isozumi, J. Appl. Phys. 68, 1735 (1990).

${ }^{14}$ Y. J. Kim, Y. Gao, and S. A. Chambers, Surf. Sci. 371, 358 (1997).

${ }^{15}$ Y. Gao, Y. J. Kim, G. Bai, and S. A. Chambers, J. Vac. Sci. Technol. A 15, 332 (1997).

${ }^{16}$ A. Muan, Am. J. Sci. 256, 171 (1958).

${ }^{17}$ D. M. Lind, S. D. Berry, G. Chern, H. Mathias, and L. R. Testardi, Phys. Rev. B 45, 1838 (1992).

${ }^{18}$ J. M. Gaines, P. J. H. Bloemen, J. T. Kohlhepp, C. W. T. Bulle-
Lieuwma, R. M. Wolf, A. Reinders, R. M. Jungblut, P. A. A. van der Heijden, J. T. W. M. van Eemeren, J. van de Stegge, and W. J. M. de Jonge, Surf. Sci. 373, 85 (1997).

${ }^{19}$ F. C. Voogt, T. Hibma, G. L. Zhang, M. Hoefman, and L. Niesen, Surf. Sci. 331, 1508 (1995).

${ }^{20}$ T. Fujii, M. Takano, R. Katano, Y. Bando, and Y Isozumi, J. Appl. Phys. 666, 3168 (1989).

${ }^{21}$ E. Pehlke, N. Moll, A. Kley, and M. Scheffler, Appl. Phys. A (to be published).

${ }^{22}$ R. A. McKee, F. J. Walker, E. D. Specht, G. E. Jellison, L. R. Boatner, and J. H. Harding, Phys. Rev. Lett. 72, 2741 (1994).

${ }^{23}$ G. H. Vurens, V. Maurice, M. Salmeron, and G. A. Somorjai, Surf. Sci. 268, 170 (1992).

${ }^{24}$ M. Ritter, H. Over, and W. Weiss, Surf. Sci. 371, 245 (1997).

${ }^{25}$ H. C. Galloway, J. J. Benitez, and M. Salmeron, Surf. Sci. 298, 127 (1993).

${ }^{26}$ C. S. Fadley, M. A. Van Hove, Z. Hussain, and A. P. Kaduwela, J. Electron Spectrosc. Relat. Phenom. 75, 273 (1995).

${ }^{27}$ H. C. Galloway, P. Sautet, and M. Salmeron, Phys. Rev. B 54, R11 145 (1996).

${ }^{28}$ H. C. Galloway, J. J. Benitez, and M. Salmeron, J. Vac. Sci. Technol. A 12, 2302 (1994).

${ }^{29}$ G. Tarrach, D. Bürgler, T. Schaub, R. Wiesendanger, and H.-J. Güntherodt, Surf. Sci. 285, 1 (1993).

${ }^{30}$ R. Jansen, V. A. M. Brabers, and H. van Kempen, Surf. Sci. 328, 237 (1995).

${ }^{31}$ A. R. Lennie, N. G. Condon, F. M. Leibsle, P. W. Murray, G. Thornton, and D. J. Vaughan, Phys. Rev. B 53, 10244 (1996).

${ }^{32}$ N. G. Condon, F. M. Leibsle, A. R. Lennie, P. W. Murray, D. J. Vaughan, and G. Thornton, Phys. Rev. Lett. 75, 1961 (1995).

${ }^{33}$ N. G. Condon, F. M. Leibsle, T. Parker, A. R. Lennie, D. J. Vaughan, and G. Thornton, Phys. Rev. B 55, 15885 (1997).

${ }^{34}$ W. Weiss, M. Ritter, D. Zscherpel, M. Swoboda, and R. Schlögl, J. Vac. Sci. Technol. (to be published).

${ }^{35}$ U. Scheithauer, G. Meyer, and M. Henzler, Surf. Sci. 178, 441 (1986). 
${ }^{36}$ W. Ranke, D. Zscherpel, W. Weiss and R. Schlögl (unpublished).

${ }^{37}$ M. A. Van Hove, W. H. Weinberg, and C.-M. Chan, Low-Energy Electron Diffraction (Springer-Verlag, Berlin, 1986).

${ }^{38}$ W. Weiss, D. Schmeisser, and W. Göpel, Surf. Sci. 207, 401 (1989).

${ }^{39} \mathrm{M}$. Henzler and W. Göpel, Oberfächenphysik des Festkörpers (Teubner Studienbücher, Stuttgart, 1994).

${ }^{40}$ W. Kleber, Einführung in die Kristallographie (VEB Verlag Technik, Berlin, 1979).

${ }^{41}$ W. Weiss, M. Ritter, and R. Schlögl (unpublished).

${ }^{42}$ W. Weiss, Surf. Sci. 377, 943 (1997).
${ }^{43}$ L. S. Darken and R. W. Gurry, J. Am. Chem. Soc. 67, 1398 (1945).

${ }^{44}$ Th. Schedel-Niedrig, W. Weiss, and R. Schlögl, Phys. Rev. B 52, 17449 (1995).

${ }^{45}$ P. W. Tasker, J. Phys. C 12, 4977 (1979).

${ }^{46}$ A. Barbieri, W. Weiss, M. A. Van Hove, and G. A. Somorjai, Surf. Sci. 302, 259 (1994).

${ }^{47}$ D. Cappus, M. Haßel, E. Neuhaus, M. Heber, F. Rohr, and H.-J. Freund, Surf. Sci. 337, 268 (1995).

${ }^{48}$ W. Schweika, A. Hoser, M. Martin, and A. E. Carlsson, Phys. Rev. B 51, 15771 (1995). 